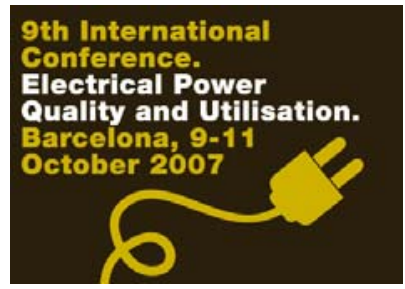

\title{
Energy Efficient Transformer Selection Implementing Life Cycle Costs and Environmental Externalities
}

\author{
Eleftherios I. Amoiralis ${ }^{1}$, Marina A. Tsili ${ }^{2}$, Pavlos S. Georgilakis ${ }^{1}$, and Antonios G. Kladas ${ }^{2}$ \\ ${ }^{1}$ Department of Production Engineering and Management \\ Technical University of Crete \\ Chania, Greece \\ eamir@tee.gr \\ pgeorg@dpem.tuc.gr \\ ${ }^{2}$ Faculty of Electrical \& Computer Engineering \\ National Technical University of Athens \\ Athens, Greece \\ mtsili@central.ntua.gr \\ kladasel@central.ntua.gr
}

\begin{abstract}
The goal of this article is to encourage electric utilities and potential investors to purchase and install high-efficiency distribution transformers where they are cost-effective. This paper proposes a methodology that implements the complex economic analyses needed to accurately determine the emissionreduction potential of high-efficiency distribution transformers. This methodology properly introduces the environmental cost into the life cycle cost (total owning cost) calculations implemented by electric utilities, and its results are compared to the classical total owning cost (without environmental cost), indicating the importance of environmental aspects of transformer economy evaluation, which may affect significantly the currently-employed transformer purchasing policy in the near future. Moreover, a sensitivity analysis of the various factors involved in the transformer life cycle cost is implemented, factors such as the transformer loading profile, the specific characteristics of the network where the transformer is installed and the uncertainty of the environmental cost impact on the final energy cost.
\end{abstract}

Keywords-component; distribution transformers; Total Owning Cost; environmental externalities; sensitivity analysis;

\section{INTRODUCTION}

The distribution transformer is the most important single piece of electrical equipment installed in electrical distribution networks with a large impact on the network's overall cost, efficiency and reliability. Selection and acquisition of distribution transformers which are optimized for a particular distribution network, the utility's investment strategy, the network's maintenance policies and local service and loading conditions will provide definite benefits (improved financial and technical performance) for both utilities and their customers [1][2].

Many electrical distribution utilities claim that they purchase distribution transformers using some type of loss evaluation procedure. Over the past 25 years, these purchasing practices have been established, as the utilities have apparently become aware of the range and the value of distribution transformer losses [3]. On the other hand, very few industrial and commercial customers include evaluation of distribution transformer losses in the purchasing process [4][5]. References [6][7] proposed an evaluation technique from the industrial and commercial customers' point of view. Moreover, the expected large increases in energy demand and the need to undertake effective measures to protect the environment could be partially solved by improvements in energy efficiency of distribution transformers. Optimized distribution transformers (costeffective and highly efficient designs) would provide numerous global benefits to the wider public as well as local benefits to electrical distribution companies, their customers and other users of distribution transformers [8][9][10].

The origin of this work lies in the fact that nowadays there is an increased interest in the protection of the environment from greenhouse gas emissions. In addition, green certificates markets are in operation in various electricity markets all over the world. For an electric utility (Distribution Company) that has numerous distribution transformers in its network, there is an opportunity to install high efficient distribution transformers that have less total energy losses than less efficient transformers, so they pollute the environment less. Bearing all these into mind, the goal of this work is to redefine the Total Owning Cost (TOC) method to properly incorporate all the aspects of the transformer life cycle, evaluating not only the 
transformer losses but also the environmental externalities. Moreover, the paper deals with current economic evaluation practices adopted by electrical utilities and industrial/commercial customers in selecting distribution transformers. To compare and assess these practices, proper analysis tools are proposed, taking into account environmental economics into the TOC equation. Further special characteristics embedded in the proposed analysis reinforce its robustness and novelty, compared to other approaches proposed in the relevant literature. Additional factors which incorporate the reliability cost associated with the loss of load probability due to transformer failures are also included into the TOC formula. Section II clearly illustrates the proposed method for the calculation of the environmental cost as well as the TOC with and without the environmental cost. Section III shows the different way that the economic evaluation is carried out for commercial/industrial transformer users. Section IV is dedicated to results and discussion. Section V presents sensitivity analysis results when varying various parameters involved in the TOC formula. Section VI concludes the paper.

\section{ECONOMIC EVALUATION METHOD FOR ELECTRIC UTILITIES}

\section{A. Total Owning Cost technique}

The most widely used technique for the evaluation of distribution transformers is the TOC method [11] that is based on the following formula:

$$
T O C=B P+A \cdot N L L+B \cdot L L
$$

where $T O C$ indicates the Total Owning Cost in $€, B P$ refers to the purchasing price of the distribution transformer in $€, A$ indicates the equivalent no-load loss cost rate in $€ / \mathrm{W}, N L L$ refers to no-load loss in $\mathrm{W}, B$ indicates the equivalent load loss cost rate in $€ / \mathrm{W}$, and $L L$ refers to load loss in W. The optimum transformer is the one with the minimum TOC. The A and $\mathrm{B}$ coefficients are computed as follows:

$$
\begin{gathered}
A=\frac{L I C+E L \cdot A F \cdot H P Y}{C R F} \\
B=\frac{L I C+E L \cdot L F \cdot H P Y}{C R F}
\end{gathered}
$$

where $L I C$ indicates the levelized annual generation and transmission system investment cost in $€ / \mathrm{W}, E L$ refers to the cost of electricity in $€ / \mathrm{kWh}, A F$ represents the transformer availability factor (i.e. the proportion of time that it is predicted to be energized, which may be less than unity due to failures), $H P Y$ indicates the hours of operation per year (typically 8760 hours), $C R F$ refers to the capital recovery factor, and $L F$ refers to the loss factor that derives from the load factor $l_{f}$ (i.e. the mean transformer loading over its lifetime, represented as an equivalent percentage of its nominal power) as follows:

$$
L F=0.15 \cdot l_{f}+0.85 \cdot l_{f}^{2}
$$

The equation yielding the $C R F$ is as follows:

$$
C R F=\frac{i \cdot(1+i)^{B L}}{(1+i)^{B L}-1}
$$

where $i$ refers to discount rate, and $B L$ refers to the number of years of the transformer lifetime.

\section{B. Methodology for the calculation of the proposed environmental cost coefficient}

Pollution resulting from electricity generation can be broadly categorized as having local, regional, and global environmental consequences. Regional and global impacts are caused primarily by the emission of atmospheric pollutants that have longer residence times, causing dispersal over large areas. Most important among these gases is $\mathrm{CO}_{2}$, which is a greenhouse gas and can contribute to global warming [12].

Each $\mathrm{kWh}$ has an external cost, i.e. the environmental and health costs to society that are not fully reflected in the price of electricity. These externalities originate in the various types of emissions resulting from the combustion of fossil fuel. In this Section, a methodology for calculating greenhouse gas emissions (carbon dioxide $\left(\mathrm{CO}_{2}\right)$, methane $\left(\mathrm{CH}_{4}\right)$, and nitrous oxide $\left(\mathrm{N}_{2} \mathrm{O}\right)$ ) is applied [13] in order to determine the equivalent emissions corresponding to each $\mathrm{MWh}$ of produced energy and yield their environmental cost. These pollutants have become a major concern for most European countries. Therefore, the main goal is to measure these emissions and to illustrate them by an environmental cost coefficient, i.e. a penalty value that will be added to the electricity cost. It may be noted that, although the above environmental costs depend on the generation technology and are not directly linked to distribution transformers, transformer owners should assume these costs as transformer losses correspond to a surplus of energy that must be produced by the existing generation mix of the power system where they are connected. According to the type of fuel (i.e. coal, diesel, natural gas, wind etc), gas emissions are converted into equivalent $\mathrm{CO}_{2}$ emissions (measured in $t_{\mathrm{CO}_{2}}$, i.e. tonnes of equivalent $\mathrm{CO}_{2}$ emissions) in terms of their global warming potential. In order to estimate the emission factor of each fuel type, the following equation is used:

$$
\mathrm{GHG}_{\mathrm{Fuel}_{i}}=\left(G_{\mathrm{CO}_{2}}+G_{\mathrm{CH}_{4}} \cdot 21+G_{\mathrm{N}_{2} \mathrm{O}} \cdot 310\right) \cdot \frac{0.0036}{n_{f_{u e l}} \cdot\left(1-J_{T-D}\right)}
$$

where $G H G_{\text {Fuel }_{i}}$ is the emission factor of each fuel type in $t_{\mathrm{CO}_{2}} / \mathrm{MWh}, \mathrm{G}_{\mathrm{CO}_{2}}$ is the $\mathrm{CO}_{2}$ emission factor in $\mathrm{kg} / \mathrm{GJ}, G_{\mathrm{CH}_{4}}$ is the $\mathrm{CH}_{4}$ emission factor in $\mathrm{kg} / \mathrm{GJ}, G_{N_{2} \mathrm{O}}$ is the $\mathrm{N}_{2} \mathrm{O}$ emission factor in $\mathrm{kg} / \mathrm{GJ}, J_{T-D}$ represents the transmission and distribution losses in $\%$, and $n_{\text {fuel }_{i}}$ is the fuel conversion efficiency in \%. The factor 0.0036 in equation (6) is used so as to convert $\mathrm{kg} / \mathrm{GJ}$ into $\mathrm{t} / \mathrm{MWh}$. It can be seen from equation (6) that $\mathrm{CH}_{4}$ and $\mathrm{N}_{2} \mathrm{O}$ emissions are converted into equivalent $\mathrm{CO}_{2}$ emissions by multiplying their emission factors with 21 and 310 respectively (theses values are provided by the Intergovernmental Panel on Climate Change). $\mathrm{CH}_{4}$ is thus 21 times more powerful a greenhouse gas than $\mathrm{CO}_{2}$, and $\mathrm{N}_{2} \mathrm{O}$ is 310 times more powerful than $\mathrm{CO}_{2}$. Taking into consideration 
equation (6) and the participation percentage of each fuel type for the electric utility system of Table I, the equivalent tonnes of $\mathrm{CO}_{2}$ emissions per year is $0.8936 t_{\mathrm{CO}_{2}} / \mathrm{MWh}\left(C_{e q}\right)$ for this specific electric utility. The typical range of $\mathrm{CO}_{2}$ emissions cost factor in the considered electric utility is between 8 and 20 $€ / t_{\mathrm{CO}_{2}}$. Assuming a moderate value of $10 €$ per $t_{\mathrm{CO}_{2}}$, the resulting environmental cost coefficient, $C$, is equal to 8.936 $€ / \mathrm{MWh}$.

TABLE I. CALCUlation EXAMPLE of THE EQUIVALENT $\mathrm{CO}_{2}$ EMISSION FACTOR $C_{e q}$ ACCORDING TO THE PARTICIPATION OF EACH FUEL TYPE TO THE Total Power Production of An Electric Utility System.

\begin{tabular}{|c|c|c|c|c|c|}
\hline Fuel type & Coal & Diesel & Hydro & $\begin{array}{c}\text { Natural } \\
\text { gas }\end{array}$ & Wind \\
\hline Fuel participation (\%) & 69.77 & 7.6 & 7.6 & 15 & 0.03 \\
\hline$G_{\mathrm{CO}_{2}}(\mathrm{~kg} / \mathrm{GJ})$ & 94.6 & 74.1 & 0.0 & 56.1 & 0.0 \\
\hline$G_{\mathrm{CH}_{4}}(\mathrm{~kg} / \mathrm{GJ})$ & 0.002 & 0.002 & 0.0 & 0.003 & 0.0 \\
\hline$G_{N_{2} O}(\mathrm{~kg} / \mathrm{GJ})$ & 0.003 & 0.002 & 0.0 & 0.001 & 0.0 \\
\hline$n_{\text {fuel }_{i}}(\%)$ & 35 & 30 & 100 & 45 & 100 \\
\hline$J_{T-D}(\%)$ & 8 & 8 & 8 & 8 & 8 \\
\hline $\mathrm{GHG}_{\mathrm{Fuel}_{i}}\left(t_{\mathrm{CO}_{2}} / \mathrm{MWh}\right)$ & 1.069 & 0.975 & 0.0 & 0.491 & 0.0 \\
\hline$C_{e q}=\frac{69.77}{100} \cdot 1.069+\frac{7.6}{100}$. & $75+\frac{15}{100}$ & $491=$ & $36 \frac{t_{\mathrm{CO}_{2}}}{\mathrm{MWh}}$ & & \\
\hline
\end{tabular}

C. Proposed TOC methodology including environmental cost

In this Section, a methodology for the calculation of the environmental cost is proposed. Afterwards, the environmental cost is incorporated into the TOC formula. The main aspect of this methodology is to quantify the penalties associated to emissions due to transformer losses, overcoming the difficulty to define the exact contribution of each transformer to these emissions. For that purpose, a reference transformer is selected, i.e. a transformer with reference no-load losses $N L L_{r}$ and reference load losses $L L_{r}$. For any given transformer that has total energy losses less than the total energy losses of the reference transformer, there is no environmental penalty, otherwise, an environmental cost is calculated. The key of computing the aforementioned environmental cost is to find the energy losses that stem from the difference between the total energy losses of the given transformer and the total energy losses of the reference transformer.

Initially, the annual energy losses corresponding to the noload losses of each given transformer are calculated $\left(E_{N L L o}\right.$ in $\mathrm{kWh} / \mathrm{yr})$ by multiplying the given no-load losses $\left(N_{L L o}\right.$ in $\left.\mathrm{kW}\right)$ by the availability factor $(A F)$ and the total number of hours per year, based on the following equation:

$$
E_{N L L o}=N L L_{o} \cdot A F \cdot H P Y
$$

Similarly, the annual energy losses corresponding to the load losses are calculated $\left(E_{L L o}\right.$ in $\left.\mathrm{kWh} / \mathrm{yr}\right)$ by multiplying the given load losses $\left(L L_{o}\right.$ in $\left.\mathrm{kW}\right)$ of each given transformer by the load factor $\left(l_{f}\right)$ and the total number of hours per year:

$$
E_{L L o}=L L_{o} \cdot l_{f}^{2} \cdot H P Y
$$

The total annual energy losses $\left(E_{L o}\right.$ in $\left.\mathrm{kWh} / \mathrm{yr}\right)$ of the given transformer are reached by adding the above-mentioned energy losses, using the equation:

$$
E_{L o}=E_{N L L o}+E_{L L o}
$$

The same procedure is followed so as to compute the total annual energy losses of the reference transformer $\left(E_{L r}\right.$ in $\mathrm{kWh} / \mathrm{yr}$ ), as follows:

$$
\begin{gathered}
E_{N L L r}=N L L_{r} \cdot A F \cdot H P Y \\
E_{L L r}=L L_{r} \cdot l_{f}^{2} \cdot H P Y \\
E_{L r}=E_{N L L r}+E_{L L r}
\end{gathered}
$$

where $E_{N L L r}$ and $E_{L L r}$ are the annual energy losses due to noload losses and load losses, respectively, for the reference transformer.

The next step consists of the comparison of the total annual energy losses of each offered transformer with the total annual energy losses of the reference transformer. In particular, if $E_{L r}<E_{L o}$, then the surplus of energy losses of each offered transformer is computed, and by multiplying this surplus with the environmental cost coefficient $C$ (calculated in Section II.B), the annual environmental cost of each offered transformer is found. Otherwise, if $E_{L r} \geq E_{L o}$, then the corresponding annual environmental cost is considered negative, providing a further incentive for transformer owners to invest to low loss designs. Finally, in order to find the total environmental cost $\left(C_{e}\right.$ in $\left.€\right)$ during the transformer lifespan, the annual environmental cost is multiplied by the transformer book-life $(B L)$, as follows:

$$
C_{e}=\left\{\begin{array}{l}
-\left|E_{L o}-E_{L r}\right| \cdot C \cdot B L, \quad \text { if } E_{L r} \geq E_{L o} \\
\left|E_{L o}-E_{L r}\right| \cdot C \cdot B L, \quad \text { if } E_{L r}<E_{L o}
\end{array}\right.
$$

For the sake of simplicity in the above calculations, $C$ has been considered constant throughout the transformer lifetime.

The total environmental cost is incorporated into the TOC formula of equation (1), resulting in the following equation:

$$
T O C_{e}=B P+A \cdot N L L+B \cdot L L+C_{e}
$$

1) Example: It is given that $A F=1, l_{f}=0.5, N L L_{r}=300 \mathrm{~W}$, $N L L_{o}=431 \mathrm{~W}, L L_{r}=2000 \mathrm{~W}, L L_{o}=2284 \mathrm{~W}, C=8.936 € / \mathrm{MWh}$. Using equations (7) to (12) we obtain $E_{N L L o}=3775.56 \mathrm{kWh} / \mathrm{yr}$, $E_{L L o}=5001.96 \mathrm{kWh} / \mathrm{yr}, \quad E_{L o}=8777.52 \mathrm{kWh} / \mathrm{yr}, \quad E_{N L L r}=2628$ $\mathrm{kWh} / \mathrm{yr}, E_{L L r}=4380 \mathrm{kWh} / \mathrm{yr}, E_{L r}=7008 \mathrm{kWh} / \mathrm{yr}$. Next, equation (13) gives that the total environmental cost for the examinant distribution transformer during its lifespan is $C_{e}=395.31 €$. 


\section{ECONOMIC EVALUATION METHOD FOR INDUSTRIAL AND COMMERCIAL USERS}

Commercial and industrial transformer purchasers can use a more simplified but effective approach for evaluating transformer losses [14]. This involves the same formula used by electric utilities, (1), but a different calculation procedure for the coefficients $A$ and $B$, without taking into account the total environmental cost. The equivalent first cost of no-load losses for any particular transformer can be calculated as follows:

$$
A=P W \cdot E L \cdot H P Y
$$

where $P W$ indicates the present worth of an inflation series for the given transformer life and discount rate, $E L$ indicates the cost of electricity in $€ / \mathrm{kWh}$, and $H P Y$ indicates the hours of operation per year. The $P W$ is calculated as follows:

$$
P W=\frac{1}{(1+i)^{B L}}
$$

where $i$ refers to discount rate, and $B L$ refers to the number of years of the transformer lifetime. The equivalent first cost of load losses (factor $B$ ) for any particular transformer can be calculated as follows:

$$
B=A \cdot P^{2} \cdot T
$$

where $P$ refers to per unit load (equivalent to the load factor $l_{f}$ ), and $T$ refers to a load loss temperature correction factor to correct specified temperatures, e.g. for liquid-filled transformers the factor $T$ is 1 since efficiency is stated at $55^{\circ} \mathrm{C}$.

In the case of commercial and industrial transformer users, the environmental cost introduction is meaningless since the environmental impact is not included in the electricity price that they have to pay due to the transformer losses. Therefore, in contrast to the electric utilities, which must take into account possible economic burdens due to the environmental impact of their generation units emissions for the economic evaluation of transformer losses, commercial and industrial users may disregard this cost.

\section{RESUlTS AND DiscUSSION}

\section{A. Transformer models under consideration}

To illustrate the impact of the specific operational transformer characteristics on the resulting TOC values, a three-phase oil-immersed distribution transformer, $50 \mathrm{~Hz}, 160$ $\mathrm{kVA}$, is considered, surveying its energy-efficient performance according to the nine different models of Table II (model 1 to model 9 is symbolized as $D_{1}$ to $D_{9}$ ). As reference transformer, the transformer with loss category $\mathrm{CC}^{\prime}$ according to CENELEC [15] is selected, which means that $N L L_{r}=300 \mathrm{~W}$ and $L L_{r}=2000 \mathrm{~W}$.

\section{B. TOC results for an electric utility}

For the case study of the electric utility, it is assumed that $A F=1, l_{f}=0.5, i=8 \%, H P Y=8760 \mathrm{~h}, B L=25$ years, $E L=0.054$ $€ / \mathrm{kWh}, C R F=0.0937, L I C=147.54 € / \mathrm{kW}, C=8.936 € / \mathrm{MWh}$. Using equations (2) and (3), it is found that $A=6.63 € / \mathrm{W}$ and
$B=3.1 € / \mathrm{W}$. Then, Table III presents the TOC results for the 9 different models, with and without the introduction of the environmental cost.

TABLE II. NINE DIFFERENT TRANSFORMER MODELS FOR THE 160 KVA DISTRIBUTION TRANSFORMER.

\begin{tabular}{lccc}
\hline $\begin{array}{l}\text { Transformer } \\
\text { model }\end{array}$ & $\begin{array}{c}\text { Bid } \\
\text { price }(\boldsymbol{\epsilon})\end{array}$ & $\begin{array}{c}\text { No-load } \\
\text { losses }(\boldsymbol{W})\end{array}$ & $\begin{array}{c}\text { Load losses } \\
(\boldsymbol{W})\end{array}$ \\
\hline $\mathrm{D}_{1}$ & 6630 & 486 & 2674 \\
$\mathrm{D}_{2}$ & 6750 & 403 & 2674 \\
$\mathrm{D}_{3}$ & 7012 & 344 & 2697 \\
$\mathrm{D}_{4}$ & 6270 & 481 & 3522 \\
$\mathrm{D}_{5}$ & 6390 & 399 & 3522 \\
$\mathrm{D}_{6}$ & 6512 & 345 & 3475 \\
$\mathrm{D}_{7}$ & 6872 & 527 & 2280 \\
$\mathrm{D}_{8}$ & 7030 & 431 & 2284 \\
$\mathrm{D}_{9}$ & 7478 & 342 & 2247 \\
\hline
\end{tabular}

TABLE III. ELECTRIC UTILITY-BASED TOC RESUltS With AND WITHOUT ENVIRONMENTAL COST.

\begin{tabular}{lcccc}
\hline $\begin{array}{l}\text { Transformer } \\
\text { model }\end{array}$ & $\begin{array}{c}\text { TOC without } \\
\text { environmental } \\
\text { cost }(\boldsymbol{\epsilon})\end{array}$ & $\begin{array}{c}\text { Total } \\
\text { environmental } \\
\text { cost }(\boldsymbol{\epsilon})\end{array}$ & $\begin{array}{c}\text { TOC } \boldsymbol{e} \text { with } \\
\text { environmental } \\
\text { cost }(\boldsymbol{\epsilon})\end{array}$ & $\begin{array}{c}\text { TOC } \\
\text { variation } \\
(\%)\end{array}$ \\
\hline $\mathrm{D}_{1}$ & 18112 & 693 & 18806 & 3.83 \\
$\mathrm{D}_{2}$ & 17682 & 531 & 18213 & 3.00 \\
$\mathrm{D}_{3}$ & 17624 & 427 & 18051 & 2.42 \\
$\mathrm{D}_{4}$ & 20339 & 1098 & 21438 & 5.40 \\
$\mathrm{D}_{5}$ & 19916 & 938 & 20854 & 4.71 \\
$\mathrm{D}_{6}$ & 19535 & 809 & 20344 & 4.14 \\
$\mathrm{D}_{7}$ & 17408 & 581 & 17989 & 3.34 \\
$\mathrm{D}_{8}$ & 16942 & 395 & 17338 & 2.33 \\
$\mathrm{D}_{9}$ & 16686 & 203 & 16889 & 1.22 \\
\hline
\end{tabular}

As it can be observed, although $D_{9}$ has the highest bid price (Table II) and it seems the worst investment, in long term, Table III clearly illustrates that $D_{9}$ is the most profitable investment, having the lowest TOC value equal to $16686 €$. Moreover, the incorporation of the environmental cost results in an increase of the TOC value of up to $5.4 \%$, which is quite considerable in case of investments for purchasing numerous distribution transformers in the electric utility sector. As a general rule, transformers with lower losses, like $D_{9}$, cost more. However, despite its high purchasing cost, this type of transformer is the best investment in the long term, since it has the lowest $T O C$ and $T O C_{e}$.

\section{TOC results for an industrial / commercial user}

For the case study of a commercial / industrial user, it is assumed that $A F=1, P=0.5, i=8 \%, B L=25$ years, $T=1$ and $E L=0.07 € / \mathrm{kWh}$. Using equations (15), (17), and (16), it is found that $A=7.069 € / \mathrm{W}$ and $B=1.767 € / \mathrm{W}$, and $P W=11.53$. Table IV presents the TOC results for the nine different 
models. As mentioned in Section III, in this case, the environmental cost is not taken into account. Once again, the $D_{9}$ is proven to be the most energy efficient one, despite its high bid price. Table IV also provides the payback period (in years) of the investment, which is calculated according to the following equation:

$$
\text { Payback Period }_{D_{i}}=\frac{B P_{D_{i}}-B P_{D_{9}}}{E L \cdot\left(E_{L o}^{D_{i}}-E_{L o}^{D_{9}}\right)}
$$

The denominator of equation (18) corresponds to the difference in the cost of energy losses between the considered model and the best model $\left(D_{9}\right)$, while the numerator corresponds to the difference in their purchasing cost.

TABLE IV. TOC RESULTS FOR THE COMMERCIAL / INDUSTRIAL USER.

\begin{tabular}{lcc}
\hline $\begin{array}{l}\text { Transformer } \\
\text { model }\end{array}$ & $\begin{array}{c}\text { TOC without } \\
\text { Environmental cost }(\boldsymbol{\epsilon})\end{array}$ & Payback Period (years) \\
\hline $\mathrm{D}_{1}$ & 14792 & 5.52 \\
$\mathrm{D}_{2}$ & 14325 & 7.08 \\
$\mathrm{D}_{3}$ & 14210 & 6.64 \\
$\mathrm{D}_{4}$ & 15895 & 4.30 \\
$\mathrm{D}_{5}$ & 15435 & 4.72 \\
$\mathrm{D}_{6}$ & 15093 & 5.08 \\
$\mathrm{D}_{7}$ & 14627 & 5.11 \\
$\mathrm{D}_{8}$ & 14114 & 7.44 \\
$\mathrm{D}_{9}$ & 13867 & - \\
\hline
\end{tabular}

\section{Transformer Efficiency}

An alternative approach to the evaluation of a transformer based on its no-load and load losses is to measure its energy efficiency at a specific load or in a given load spectrum. The general expression for efficiency is [14]:

$$
E=\frac{100 \cdot P \cdot k V A \cdot 1000}{P \cdot k V A \cdot 1000+N L L+L L \cdot P^{2} \cdot T}
$$

where $k V A$ refers to the rated power (in $\mathrm{kVA}$ ). We have $T=1$ since efficiency is stated at $55{ }^{\circ} \mathrm{C}$. Fig. 1 illustrates the transformer efficiency for the nine different models in a specific load spectrum, i.e. from $10 \%$ to $130 \%$ loading, using loading step equal to $10 \%$, corresponding to $\mathrm{P}$ spectrum $[0.1$ 1.3]. As shown in Fig. $1, D_{9}$ seems the most efficient transformer in comparison with the other models, while $D_{4}$ and $D_{5}$ seem the least efficient transformers.

\section{SENSITIVITY ANALYSIS}

In the $T O C$ economic analysis, it is helpful to determine how sensitive the $T O C_{e}$ is to several factors of concern so that proper consideration may be given to them in the decision process. The factors that are selected are: the load factor $\left(l_{f}\right)$, the discount rate $(i)$, the cost of electricity $(E L)$, the levelized annual generation and transmission system investment cost $(L I C)$, the environmental cost coefficient $(C)$, the availability factor $(A F)$, and the number of years of the transformer lifetime $(B L)$. These components consist the most versatile factors in the equations yielding the $A, B$ and $C_{e}$ factors of the $T O C_{e}$ calculation (from the point of view of the electric utility, which is faced with an increased uncertainty in the transformer economic evaluation process, especially during the incorporation of environmental externalities). Before we start vary the above-mentioned components, we should develop a base case of $T O C_{e}$, i.e. $T O C_{e}$ equal to $16889 €\left(\right.$ Table III - $D_{9}$ ), which corresponds to $l_{f}=0.5, i=8 \%, E L=0.054 € / \mathrm{kWh}, L I C=$ $147.54 € / \mathrm{kW}$, and $C=8.936 € / \mathrm{MWh}$. Table $\mathrm{V}$ and Fig. 2 present the sensitivity parameter analysis results, based on various components values. For example, by changing $+10 \%$ the component $L I C$, the $T_{O} C_{e}$ changes $+2.42 \%$ in comparison with the $T O C_{e}$ of the base case. It is noted that in this table, only negative variations of $A F$ are considered, since the availability factor can only be less than unity (the loss of load probability due to transformer failures can result in fewer hours of transformer operation than the total hours per year).

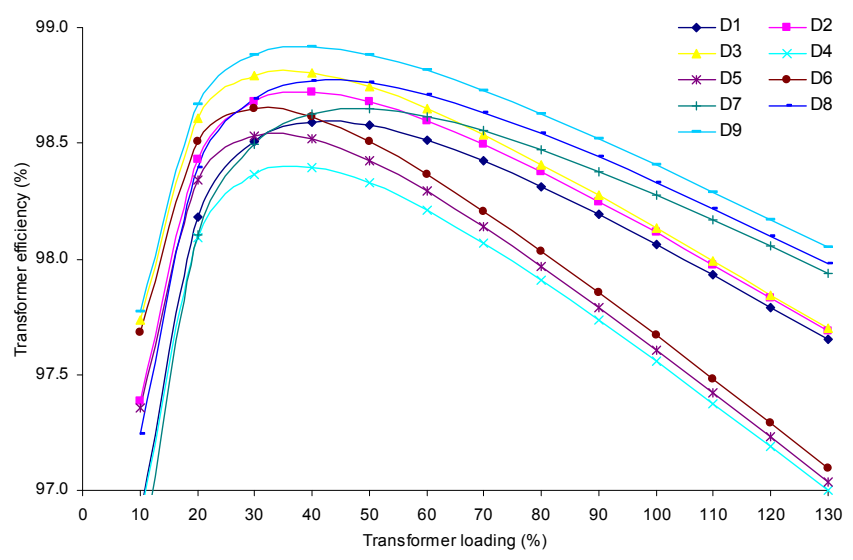

Figure 1. Transformer efficiency for each given model of transformer.

TABLE V. Sensitivity PARAMETER ANALysis. TOC VARIATION BASED ON VARYING COMPONENTS VALUES

\begin{tabular}{lccccccc}
\hline \multirow{2}{*}{$\begin{array}{l}\text { Components } \\
\text { variation (\%) }\end{array}$} & \multicolumn{6}{c}{ TOC $\boldsymbol{C}_{\boldsymbol{e}}$ variation (\%) when varying component $\boldsymbol{l}_{\boldsymbol{f}}$ to $\boldsymbol{B L}$} \\
\cline { 2 - 8 } & $\boldsymbol{l}_{\boldsymbol{f}}$ & $\boldsymbol{i}$ & $\boldsymbol{E L}$ & $\boldsymbol{L I C}$ & $\boldsymbol{C}$ & $\boldsymbol{A F}$ & $\boldsymbol{B L}$ \\
\hline-20 & -6.44 & 8.36 & -6.07 & -4.83 & -0.24 & -0.02 & -4.61 \\
-15 & -4.93 & 6.09 & -4.55 & -3.62 & -0.18 & -0.05 & -3.30 \\
-10 & -3.36 & 3.95 & -3.04 & -2.41 & -0.12 & -0.07 & -2.10 \\
-5 & -1.71 & 1.92 & -1.52 & -1.2 & -0.06 & -0.09 & -1.00 \\
5 & 1.79 & -1.81 & 1.52 & 1.21 & 0.06 & - & 0.92 \\
10 & 3.65 & -3.53 & 3.04 & 2.42 & 0.12 & - & 1.75 \\
15 & 5.57 & -5.15 & 4.56 & 3.62 & 0.18 & - & 2.52 \\
20 & 7.57 & -6.69 & 6.08 & 4.83 & 0.24 & - & 3.22 \\
\hline
\end{tabular}

Fig. 2 shows the sensitivity of the $T O C_{e}$ to percent deviation changes in each component's best estimate. The other components are assumed to remain at their best estimate values. The relative degree of sensitivity of the $T O C_{e}$ to each 
component is indicated by the slope of the curves (the steeper the slope of a curve, the more sensitive the $T O C_{e}$ is to the component) [16]. Based on this, as can be observed from Fig. 2 , the $T O C_{e}$ is for all practical purposes insensitive to environmental cost coefficient $(C)$ and availability factor $(A F)$, but quite sensitive to changes in load factor $\left(l_{f}\right)$, the discount rate $(i)$, the cost of electricity $(E L)$, the number of years of the transformer lifetime $(B L)$, and the cost of installing transmission systems (LIC). Finally, Table VI presents in brief the sensitivity results.

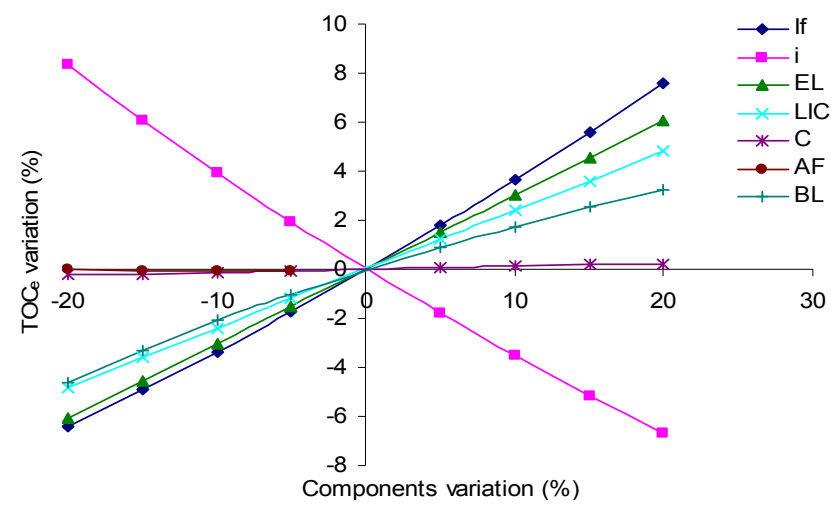

Figure 2. Sensitivity graph of seven components

The aforementioned non-probabilistic methodology, readily available, provides information about the potential impact of uncertainty in selected factor estimates.

TABLE VI. SENSITIVITY PARAMETER ANALYSIS

\begin{tabular}{lccc}
\hline $\begin{array}{l}\text { Input } \\
\text { parameters }\end{array}$ & $\begin{array}{c}\text { Input } \\
\text { variation (\%) }\end{array}$ & $\begin{array}{c}\text { Minimum TOC } \\
\text { variation (\%) }\end{array}$ & $\begin{array}{c}\text { Maximum TOC } \\
\text { variation (\%) }\end{array}$ \\
\hline$l_{f}$ & \pm 20 & -6.44 & 7.57 \\
$i$ & \pm 20 & -6.69 & 8.36 \\
$E L$ & \pm 20 & -6.07 & 6.08 \\
$L I C$ & \pm 20 & -4.83 & 4.83 \\
$C$ & \pm 20 & -0.24 & 0.24 \\
$A F$ & -20 to -5 & -0.02 & -0.09 \\
$B L$ & \pm 20 & -4.61 & 3.22 \\
\hline
\end{tabular}

\section{CONCLUSIONS}

In the present paper, a TOC economic analysis with built-in environmental cost was proposed. The differences in assessing a distribution transformer operated by an industrial/commercial owner and a distribution transformer operated by an electric utility were described. The introduction of environmental costs has resulted in a maximum increase of the $T O C_{e}$ value of $5.4 \%$, which should be considered by electric utilities, as they are already subject to rigorous European and international directives imposed for the global reduction of gas emissions due to electric power production by conventional generating units. Economic assessment adopted by commercial and industrial transformer users yields considerably different TOC values in comparison with those of electric utilities, partly because of using different formulas for calculating the $A$ and $B$ coefficients, but mainly because of using the electricity price instead of the energy cost and to a lesser extent due to the absence of environmental costs. Alternative calculations of the evaluated transformers efficiency reinforced the results provided by the $T O C_{e}$ method. Finally, sensitivity analysis was conducted so as to investigate the impact of the $T O C_{e}$ components variation in the final purchasing decision. According to this analysis, the $T O C_{e}$ variation is quite sensitive to changes in the transformer loading factor and the discount rate, while changes in the cost of energy, the transmission and generation system investment cost and the transformer lifetime duration affect it less. On the other hand, $T O C_{e}$ remains practically stable during variations in the availability factor and the environmental cost factor.

\section{ACKNOWLEDGMENT}

This paper is part of the 03ED045 research project that is co-financed by E.U.-European Social Fund $(75 \%)$ and the Greek Ministry of Development-GSRT (25\%).

\section{REFERENCES}

[1] T. J. Hammons, B. Kennedy, R. Lorand, S. Thigpen, B. W. McConnel, S. Rouse, T. A. Prevost, C. Pruess, S. J. Dale, V. R. Ramanan, T. L. Baldwin, "Future trends in energy-efficient transformers", IEEE Power Engineering Review, vol. 18, no. 7, pp. 5-16, 1998.

[2] M J McDermott and Associates, Impact of Purchasing Energy-Efficient Transformers, European Copper Institute, July 2001.

[3] B. Kennedy, Energy Efficient Transformers, Mc Graw - Hill, 1998.

[4] W. T. J. Hulshorst and J. F. Groeman, Energy Saving in Industrial Distribution Transformers, KEMA report, May 2002.

[5] P. R. Barnes, J. W. Van Dyke, B. W. McConnell, S. Das, "Determination Analysisi of Energy Conservation Standards for Distribution Transformers," Oak Ridge National Laboratory, ORNL6847, July 1996.

[6] S. Merritt, S. Chaitkin, "No Load versus Load Loss," IEEE Industry Applications Magazine, vol. 9, no 6, pp. 21-28, Nov. 2003.

[7] P. S. Georgilakis, "Decision support system for evaluating transformer investments in the industrial sector," Journal of Materials Processing Technology, vol. 181, no. 1-3, pp. 307-312, 2007.

[8] B. W. McConnell, "Increasing Distribution Transformer Efficiency: Potential for Energy Savings," IEEE Power Engineering Review, vol. 18, no 7, pp. 8-10, July 1998

[9] R. Targosz (ed) et al., The Potential for Global Energy Savings from High Energy Efficiency Distribution Transformers, Leonardo Energy, European Copper Institute, February 2005.

[10] European Copper Institute, The Scope for Energy Saving in the EU Through the Use of Energy-Efficient Electricity Distribution Transformers, December 1999.

[11] Loss Evaluation Guide for Power Transformers and Reactors, ANSI/IEEE Standard C57.120, August 1992.

[12] European Commission, External Costs: Research results on socioenvironmental damages due to electricity and transport, DirectorateGeneral for Research, Brussels, Study 20198, 2003.

[13] RETScreen International, http://www.retscreen.net.

[14] NEMA, Guide for Determining Energy Efficiency for Distribution Transformers, NEMA Standards Publication TP 1-2002.

[15] CENELEC, Harmonization Document HD428: 1 S1:1992.

[16] W. G. Sullivan, E. M. Wicks, J. T. Luxhoj, Enginnering Economy, $13^{\text {th }}$ edition,Macmillan Publishing Company,Pearson Education, 2006. 